\title{
The Key Stratum Structure Morphology of Longwall Mechanized Top Coal Caving Mining in Extra-Thick Coal Seams: A Typical Case Study
}

\author{
Fulian He, ${ }^{1}$ Xiaobin Li $\mathbb{D}^{1},{ }^{1}$ Wenrui He, ${ }^{1}$ Yongqiang Zhao, ${ }^{2}$ Zhuhe $\mathrm{Xu},{ }^{1}$ and \\ Quansheng Li ${ }^{1,2}$ \\ ${ }^{1}$ School of Energy and Mining Engineering, China University of Mining and Technology (Beijing), Beijing 100083, China \\ ${ }^{2}$ State Key Laboratory of Water Resource Protection and Utilization in Coal Mining, Beijing 102209, China \\ Correspondence should be addressed to Xiaobin Li; 1xb162197@126.com
}

Received 20 November 2019; Revised 8 July 2020; Accepted 23 July 2020; Published 28 August 2020

Academic Editor: Chunshun Zhang

Copyright (c) 2020 Fulian He et al. This is an open access article distributed under the Creative Commons Attribution License, which permits unrestricted use, distribution, and reproduction in any medium, provided the original work is properly cited.

\begin{abstract}
Longwall mechanized top coal caving mining (LMTCCM) in extra-thick coal seams has its own characteristics. The law of mining pressure and overlying strata failure height in extra-thick coal seams are much larger than those of medium-thick and thick coal seams. The key stratum structure morphology also has an important influence on the law of overlying strata movement and stability of surrounding rock. Based on the engineering geological conditions, this paper used the method of theoretical analysis and numerical simulation to study the key stratum structure morphology of LMTCCM in extra-thick coal seams. The results show that under the condition of LMTCCM in extra-thick coal seams, the key stratum forms the structure of low cantilever beam and high hinged rock beam. With the increase of coal seam thickness, the breaking position of cantilever beam is closer to the coal wall. Through theoretical calculation, it is obtained that the breaking length of cantilever beam is $31.5 \mathrm{~m}$ and the breaking position of cantilever beam is $15.4 \mathrm{~m}$ away from coal wall. With the increase of cycle, key strata will undergo the evolution law from the generation of longitudinal cracks to the hinged structure and then to the cantilever beam structure. The breakage of key strata will cause the expansion of longitudinal cracks and the overall synchronous movement of overlying strata. With the increase of coal seam thickness, the distribution of longitudinal cracks will gradually transfer from the upper part of goaf to the deep part of coal body in space and increase in quantity. This research is of great significance for improving the stability of overlying strata and ensuring the safe and efficient mining of extra-thick coal seams.
\end{abstract}

\section{Introduction}

The conventional mining height has three types, including thin coal seam (thickness $\leq 1.3 \mathrm{~m}$ ), medium-thick coal seam $(1.3 \mathrm{~m}<$ thickness $\leq 3.5 \mathrm{~m})$, and thick coal seam (thickness $>3.5 \mathrm{~m}$ ). However, with the construction of large-scale modern coal mine, extra-thick coal seam (thickness $\geq 8 \mathrm{~m}$ ) appears gradually. China has abundant coal reserves, with thick and extra-thick coal seams accounting for over $40 \%$ of the total coal reserves [1]. With the construction of high production and efficient mines, LMTCCM has become the main mining method of extrathick coal seams $[2,3]$. LMTCCM in extra-thick coal seams has its own characteristics, such as enormous coal output per panel, supper high efficiency, remarkable benefits, and so on, which plays an important leading role in the development of China's coal industry $[4,5]$. However, the increase of coal seam thickness and huge mining space make it difficult for the key strata in the overlying strata to form a stable structure [6]. The key strata are generally relatively thick and hard strata, which play a major role in controlling the activities of overlying strata in stope $[7,8]$. Violent movement of key strata may cause a series of mining damage problems, such as surface subsidence, support damage, rock burst, and water and gas disaster [9-11]. Therefore, it is of great significance to 
study the structure morphology of key strata under conditions of LMTCCM in extra-thick coal seams.

In recent years, some research has been done on LMTCCM in extra-thick coal seams. Based on the mechanical calculation, Yan et al. [12] established a mathematical model and put forward a method to judge the roof separation position above roadway, which was successfully verified in the field. By analyzing the variation law of stress, displacement, and plastic zone of surrounding rock, Fei and Jiang [13] discussed the deformation mechanism of retracement roadway in extra-thick coal seams and put forward optimal scheme to control the large deformation of roadway. Zhang [14] presented the relationship between the stability of coal pillar and the reasonable position of splitlevel longwall gob-side entry in extra-thick coal seams. Wang et al. [15] studied the relationship between horizontal section mining and rock burst under conditions of steeply inclined and extra-thick coal seam and put forward reasonable measures to prevent rock burst. Based on the specific geological conditions, Wang et al. [16] explored the distribution and emission law of gas in extra-thick coal seams. Wang et al. [17] investigated key mining technologies and equipment of LMTCCM in extra-thick coal seams and successfully applied to Tashan coal mine. By building numerical model and field measurement, Si et al. [18] and Fan et al. [19] determined the gas dynamics characteristics in multilevel longwall top coal caving of extra-thick coal seams.

In addition, many scholars also did exploratory research on key strata theory and overlying strata movement. Based on the physical similarity simulation and field surveys, Zhou et al. [20] and Yao et al. [21] determined the distribution law of dynamic ground cracks under the influence of overlying strata structure. Li et al. [22] indicated that spatial relationships between key strata have influence on the height of mining-induced fracture zone. Liang et al. [23] discussed the influence of different key strata structure types on strata behavior with large mining height. Based on the theoretical deduction, Jiang et al. [24] deeply analyzed the instability and fracture mechanism of key strata and dynamic response characteristics. Li et al. [25] demonstrated the dynamic response process of strata movement and working face mine pressure after compound breakage of key strata. Wang et al. [26] analyzed the breakage and instability mechanism of hard-thick sandstone roof and its controlling effect on gas emission. Guo et al. [27] determined roof strata characteristics and support resistance of LMTCCM in extra-thick coal seams through physical similarity simulation and field monitoring. Based on elastic mechanics theories, Li et al. [28] established mechanical model to describe the rotation speed of hinged rock beam structure formed by key strata. Based on the theory of waterproof key strata, Sun and Miao [29] developed a model of an inclined coal seam floor with linearly increasing water pressure. Wang et al. [30] and Jiang et al. [31] studied the relationship between the mining height of coal seam and overlying rock movement under the filling mining face. In view of this, Zhang et al. [32] proposed the method of adopting the short-wall block backfill mining to protection surface water resources. At the same time, the thickness of coal seam is closely related to the law of strata movement. The greater the thickness of coal seam, the more serious the strata pressure behavior $[33,34]$.

It can be seen from the above that many scholars mainly focus on the roadway, coal pillar, rock burst, and gas control in extra-thick coal seams, strata movement characteristics, and mine pressure behavior. However, there are relatively few studies on the structure morphology of key strata under conditions of LMTCCM in extra-thick coal seams, especially the geometric configuration, breaking position, and influence factors of cantilever beam structure and distribution characteristics of longitudinal cracks in space and quantity. Therefore, based on the engineering background of 8211 working face, theoretical analysis and numerical simulation are used to study the structure morphology of key strata. This research has great significance in realizing safe and efficient mining of extra-thick coal seams and improving the stability of overlying strata.

\section{Engineering Background}

2.1. Mining and Geological Conditions. The coal mine, located in Datong city, Shanxi Province, China (Figure 1), covers a mining area of $40 \mathrm{~km}^{2}$. The minefield is $8 \mathrm{~km}$ long and $5 \mathrm{~km}$ wide. The coal bearing strata belong to the Taiyuan Formation, upper carboniferous. The main minable coal seam is coal seam 5, with an average thickness of $15 \mathrm{~m}$. This research involves a representative area: the 8211 working face with a striking length of $780 \mathrm{~m}$ and an inclination length of $220 \mathrm{~m}$. Figure 2 shows the generalised stratigraphy column. The false roof is mudstone with an average thickness of $1.7 \mathrm{~m}$. The immediate roof is siltstone with an average thickness of $3.8 \mathrm{~m}$. The key strata control the movement of overlying strata to the surface, which have great influence on the mine pressure behavior $[35,36]$. Based on the criterion conditions and calculation, the key strata are determined. The key stratum 1 is medium sandstone with an average thickness of $13.5 \mathrm{~m}$. The interlayer is sandy mudstone and fine sandstone with an average thickness of $39.6 \mathrm{~m}$. The key stratum 2 is also medium sandstone with an average thickness of $13.7 \mathrm{~m}$. The immediate floor is carbonaceous mudstone with an average thickness of $5 \mathrm{~m}$. The main floor is fine sandstone with an average thickness of $10 \mathrm{~m}$.

2.2. Experiments on Rock Mechanical Properties. The breakage and instability of key strata are closely related to the mechanical properties. In order to provide mechanical parameters for theoretical analysis and numerical simulation, uniaxial compression test, splitting testm and shear strength test are carried out on rock samples [37-39]. The uniaxial compression strength, elastic modulus, and Poisson's ratio are measured by the uniaxial compression test on a total of 6 rock samples. The uniaxial tensile strength is measured by the splitting test on a total of 8 rock samples. The cohesion and internal friction angle are measured by the shear strength test on a total of 7 rock samples (Figure 3).

\section{Theoretical Analysis}

3.1. Formation Conditions of Cantilever Beam Structure. 


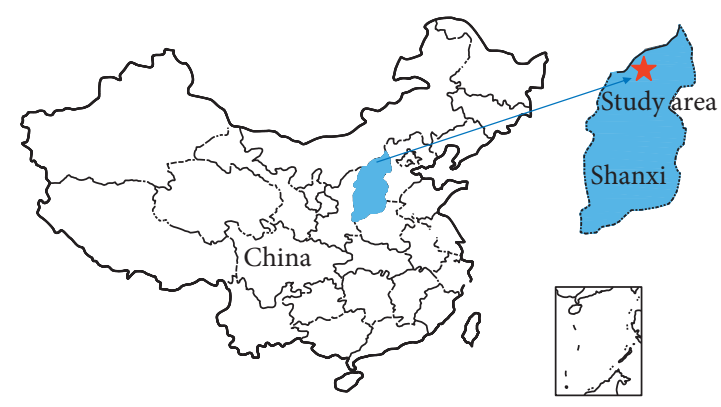

Figure 1: Location of coal mine in Datong city, Shanxi Province, China.

\begin{tabular}{|c|c|c|c|c|}
\hline Stratigraphic column & Lithology & $\begin{array}{c}\text { Thickness } \\
(\mathrm{m})\end{array}$ & Lithological description & Remarks \\
\hline & $\begin{array}{l}\text { Medium } \\
\text { sandstone }\end{array}$ & 13.7 & $\begin{array}{l}\text { Gray-white, medium-fine-grained structure, mainly } \\
\text { composed of quartz and feldspar, sandwiched with } \\
\text { thin layered silt and fine sandstone. }\end{array}$ & Key stratum 2 \\
\hline \multirow[t]{3}{*}{$=-2---2-$} & $\begin{array}{l}\text { Sandy mudstone } \\
\text { fine sandstone }\end{array}$ & 39.6 & $\begin{array}{l}\text { Black, argillaceous, massive structure, with rhizoid } \\
\text { fossils and coal debris. }\end{array}$ & Interlayer \\
\hline & $\begin{array}{l}\text { Medium } \\
\text { sandstone }\end{array}$ & 13.5 & $\begin{array}{l}\text { Gray-white, coarse-grained structure, massive } \\
\text { structure, the bottom of the gravel gradually } \\
\text { increased, mainly composed of quartz and feldspar. }\end{array}$ & Key stratum 1 \\
\hline & Siltstone & 3.8 & $\begin{array}{l}\text { Gray-white, coarse grained texture, block structure, } \\
\text { fissures are not developed. }\end{array}$ & Immediate roof \\
\hline \multirow[t]{2}{*}{$\begin{array}{r}-----1 \\
---1\end{array}$} & Mudstone & 1.7 & $\begin{array}{c}\text { Black, argillaceous, massive, more stable, more } \\
\text { developed fissures. }\end{array}$ & False roof \\
\hline & Coal seam & 15.0 & $\begin{array}{l}\text { Black, semi-dark coal dominated, with a small } \\
\text { amount of bright coal fine strips, endogenous cracks } \\
\text { developed, containing a small amount of nodules. }\end{array}$ & Coal \\
\hline \multirow[t]{2}{*}{$-1---1$} & $\begin{array}{l}\text { Carbonaceous } \\
\text { mudstone }\end{array}$ & 5.0 & $\begin{array}{l}\text { Black mud structure, block structure, containing the } \\
\text { root of fossil plants and coal. }\end{array}$ & Immediate floor \\
\hline & Fine sandstone & 10.0 & $\begin{array}{l}\text { Gray-white, medium-fine structure, block structure, } \\
\text { cracks are not developed. }\end{array}$ & Main floor \\
\hline
\end{tabular}

FIGURE 2: Generalised stratigraphy column of the test site.

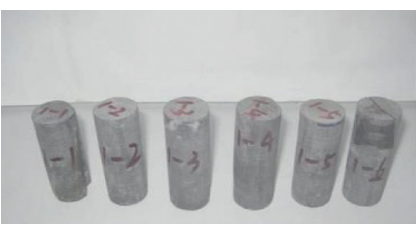

(a)

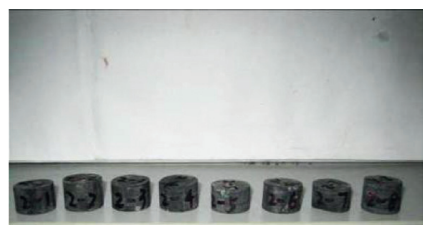

(b)

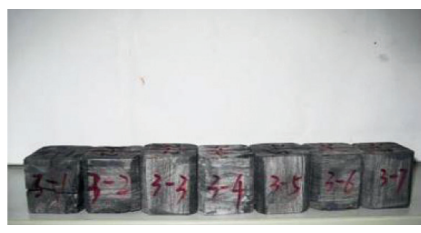

(c)

Figure 3: Rock samples used in the experiments. (a) Uniaxial compression test samples. (b) Splitting test samples. (c) Shear strength test samples.

Due to huge mining space, overlying strata move violently in LMTCCM of extra-thick coal seams. The key stratum with hinged rock beam structure can be formed at conventional mining height. Cantilever beam structure may be formed under condition of extra-thick coal seam because of large rotary deformation and instability of strata. But, the higher key stratum still can form hinged rock beam structure.
Therefore, the key stratum structure morphology is closely related to the location of key stratum and the thickness of coal seam. As shown in Figure 4, when the possible rotating amount of key block is larger than the maximum rotating amount that can ensure the formation of stable structure, cantilever beam structure will be formed. The conditions of forming cantilever beam structure are as follows: 


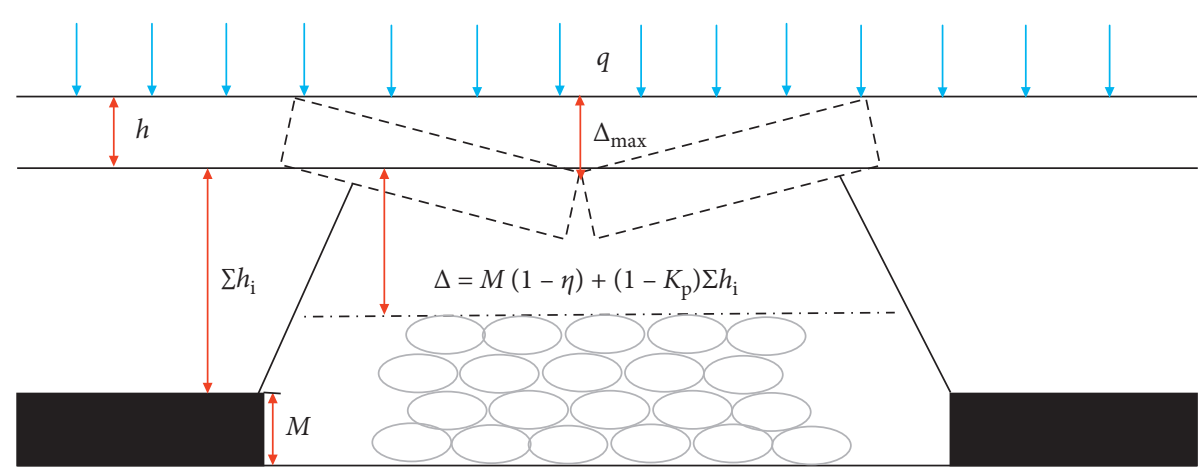

FigURE 4: Breaking and rotation movement diagram of key stratum.

$$
\Delta>\Delta_{\max }
$$

where $\Delta$ refers to the possible rotating amount of key block and $\Delta_{\max }$ is the maximum rotating amount that can ensure the formation of stable structure.

The distance between the collapsed immediate roof and the key stratum is the possible rotating amount. It can be expressed as follows [40]:

$$
\Delta=M(1-\eta)+\left(1-K_{p}\right) \sum h_{i},
$$

where $M$ is the mining thickness of coal seam; $\eta$ is the loss rate of coal caving; and $K_{p}$ is the fragmentation coefficient of collapsed strata; $\sum h_{i}$ is the thickness of immediate roof and false roof.

According to the theory of mine pressure and strata control, the maximum rotating amount is as follows:

$$
\Delta_{\max }=h-\frac{q L_{0}^{2}}{k h \sigma_{c}},
$$

where $h$ is the thickness of key stratum; $q$ is the load generated by overlying strata $(q=\gamma H) ; L_{0}$ is the periodic weighting interval of working face; $k$ is dimensionless coefficient $(k=0.1 \mathrm{~h}) ; \sigma_{\mathrm{c}}$ is the compressive strength of key strata; $\gamma$ is average bulk density of overlying strata $\left(\gamma=25 \mathrm{kN} / \mathrm{m}^{3}\right)$; and $H$ is burial depth of coal seam.

By substituting formula (2) and formula (3) into formula (1), the conditions of forming cantilever beam structure are obtained as follows [41]:

$$
M(1-\eta)+\left(1-K_{p}\right) \sum h_{i}>h-\frac{q L_{0}^{2}}{k h \sigma_{c}} .
$$

According to the engineering geological conditions of 8211 working face, the mining thickness of coal seam is $15 \mathrm{~m}$; the loss rate of coal caving is $20 \%$; the fragmentation coefficient of collapsed strata is 1.3; the thickness of immediate roof and false roof is $5.5 \mathrm{~m}$; the thickness of key stratum is $13.5 \mathrm{~m}$; the load generated by overlying strata is $10.25 \mathrm{MPa}$; the periodic weighting interval of working face is $28.6 \mathrm{~m}$; and the compressive strength of key strata is $71 \mathrm{MPa}$. The corresponding value is substituted into formula (4). The possible rotating amount of key block is $10.35 \mathrm{~m}$. The maximum

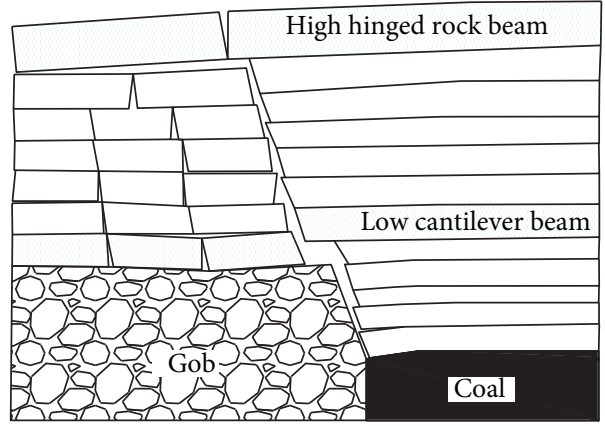

FIGURE 5: Structure characteristics of low cantilever beam and high hinged rock beam.

rotating amount that can ensure the formation of stable structure is $7.02 \mathrm{~m}$. The calculation results are in agreement with formula (4). It is concluded that the key stratum of LMTCCM in extra-thick coal seam forms the structure of low cantilever beam and high hinged rock beam, as shown in Figure 5 .

\subsection{Geometric Characteristics of Cantilever Beam Structure.} Cantilever beam structure plays an important role in the stability of stope and roadway. Sometimes, it will cause severe coal mine accidents and damage of support equipment in stope, as shown in Figure 6. Therefore, it is necessary to determine the geometric characteristics of cantilever beam structure, including its thickness, breaking length, and position on the coal wall. According to the geological conditions of 8211 working face, the thickness of cantilever beam is $13.5 \mathrm{~m}$, and the breaking length can be solved by the following formula [42]:

$$
L=L_{0}\left[\sqrt{\left(\frac{L_{0}}{S}\right)^{2}+\frac{3}{2}}-\frac{L_{0}}{S}\right],
$$

where $L$ is the breaking length of cantilever beam and $S$ is the length of working face.

According to the geological conditions of 8211 working face, the length of working face is $220 \mathrm{~m}$ and the periodic 


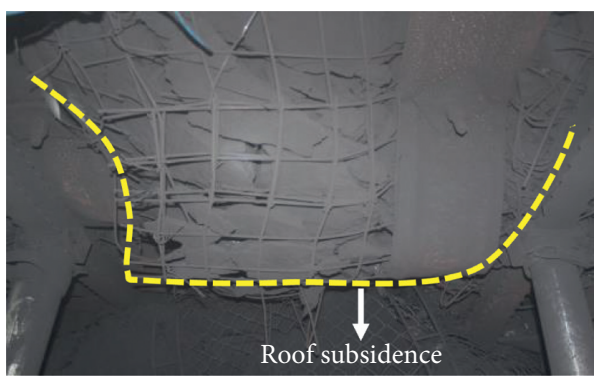

(a)

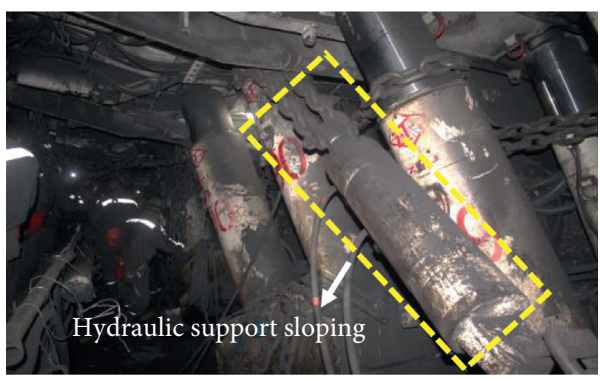

(c)

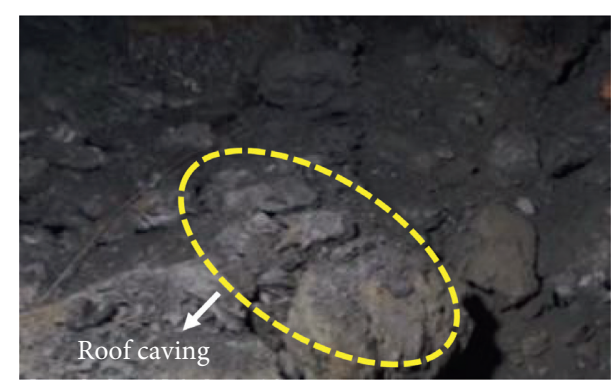

(b)

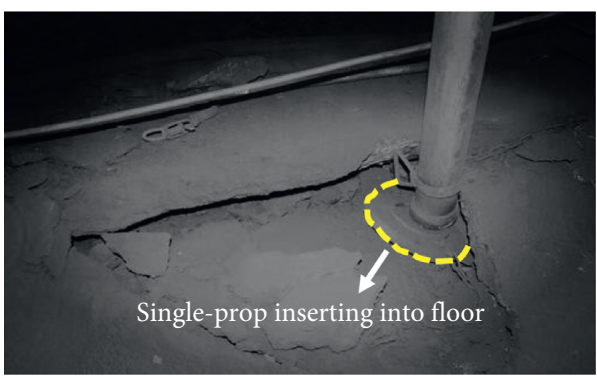

(d)

FIGURE 6: Failure patterns in LMTCCM of extra-thick coal seams.

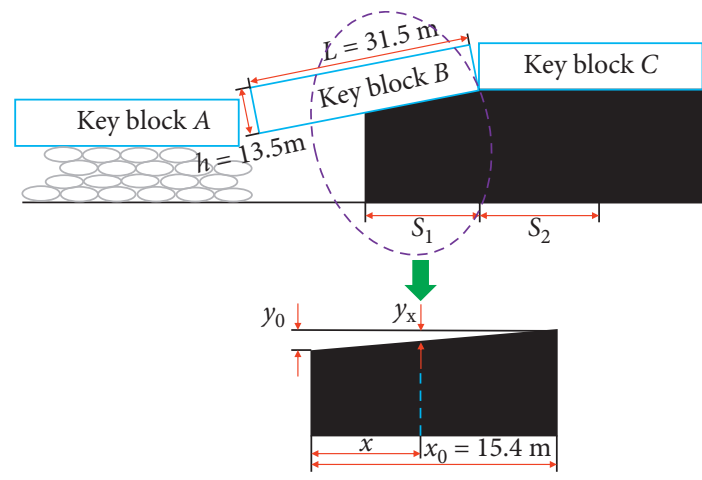

FIgURE 7: Breakage structure model of key stratum.

weighting interval of working face is $28.6 \mathrm{~m}$. The corresponding value is substituted into formula (5). Finally, the breaking length of cantilever beam is $31.5 \mathrm{~m}$.

The breaking position of cantilever beam on the coal wall can be solved by internal and external stress field theory. Figure 7 shows that cantilever beam is broken, and the pressure transferred from overlying strata to coal is divided into two parts. The internal stress field $S_{1}$ is within the breaking line and bears the weight of the strata controlled by the structure of low cantilever beam and high hinged rock beam. The external stress field $S_{2}$ is outside the breaking line and bears the weight of the upper strata and additional stress transferred from the internal stress field. It can be seen that the range of internal stress field is the breaking position of cantilever beam.

According to material mechanics, the vertical stress on the coal which is $x \mathrm{~m}$ away from coal wall within the range of internal stress field can be expressed as follows [43]:

$$
\sigma_{y}=G_{x} \cdot y_{x}
$$

where $\sigma_{y}$ is the vertical stress on the coal $x \mathrm{~m}$ away from coal wall; $G_{x}$ is the stiffness modulus of the coal $x \mathrm{~m}$ away from coal wall; and $y_{x}$ is the amount of compression of the coal $x \mathrm{~m}$ away from coal wall.

From the edge of coal wall to the depth, coal will change from two-dimensional stress state to three-dimensional stress state. The stiffness modulus of coal will increase and the vertical compression of coal will decrease. The compression deformation of coal will reach maximum at the coal wall. In order to simplify calculation, it is considered that the compression and stiffness modulus of coal vary linearly within the range of internal stress field. The equation is as follows:

$$
\frac{y_{x}}{y_{0}}=\frac{x_{0}-x}{x_{0}}, \frac{G_{x}}{G_{0}}=\frac{x}{x_{0}},
$$

where $y_{0}$ is the amount of compression of the coal at the edge of coal wall; $x_{0}$ is the range of internal stress field; and $G_{0}$ is the maximum stiffness modulus of coal in the range of internal stress field.

The vertical stress in the internal stress field can be integrated as follows:

$$
F=\int_{0}^{x_{0}} \sigma_{y} d x=\int_{0}^{x_{0}} G_{x} y_{x} d x .
$$

According to formula (7) and formula (8), the following equation can be obtained:

$$
F=\frac{G_{0} y_{0}}{x_{0}^{2}} \int_{0}^{x_{0}} x\left(x_{0}-x\right) d x=\frac{G_{0} y_{0} x_{0}}{6}
$$


The vertical stress of coal in stope during the first weighting is equal to the weight of rock strata controlled by the structure of low cantilever beam and high hinged rock beam. The following equation can be obtained:

$$
F=\frac{G_{0} y_{0} x_{0}}{6}=S C_{0} \gamma \sum_{1}^{n} h_{i},
$$

where $C_{0}$ is the first weighting interval of working face and $\sum_{1}^{n} h_{i}$ is the thickness of rock strata controlled by the structure of low cantilever beam and high hinged rock beam.

As shown in Figure 7, the geometric relations of $y_{0}$ and $x_{0}$ are as follows:

$$
\frac{y_{0}}{x_{0}}=\frac{\Delta h}{L_{0}},
$$

where $\Delta h$ is the maximum subsidence of key stratum.

According to the theory of mine pressure and strata control, the following equation can be obtained:

$$
\Delta h=M-\sum h_{i}\left(K_{p}-1\right) .
$$

According to formula (11) and formula (12), the following result can be obtained:

$$
y_{0}=\frac{x_{0}}{L_{0}}\left[M-\sum h_{i}\left(K_{p}-1\right)\right]
$$

The stiffness modulus of coal can be expressed as follows:

$$
G_{0}=\frac{E}{2(1+u) \xi}
$$

where $E$ is the elastic modulus of coal; $u$ is Poisson's ratio of coal; and $\xi$ is the integrity coefficient.

According to formula (10), formula (13), and formula (14), the range of internal stress field can be obtained as follows:

$$
x_{0}=\sqrt{\frac{12 \gamma \sum_{1}^{n} h_{i} S C_{0} L_{0} \xi(1+u)}{E\left[M-\sum h_{i}\left(K_{p}-1\right)\right]}} .
$$

Based on geological data, the thickness of rock strata controlled by the structure of low cantilever beam and high hinged rock beam is $90.6 \mathrm{~m}$; the first weighting interval of working face is $35 \mathrm{~m}$; integrity coefficient is 0.8 ; Poisson's ratio of coal is 0.36 ; the elastic modulus of coal is $2.06 \mathrm{GPa}$. The corresponding value is substituted into formula (15). The range of internal stress field is $15.4 \mathrm{~m}$. Therefore, the breaking position of cantilever beam is $15.4 \mathrm{~m}$ away from coal wall. The geometric configuration of cantilever beam is shown in Figure 7.

\subsection{Influence Factors of Cantilever Beam Breaking Position.} According to formula (15), it can be seen that there are three factors, geometric parameters, engineering parameters, and mechanical parameters, which affect the breaking position of cantilever beam. Geometric parameters of rock strata include the thickness of coal seam and immediate roof.
Engineering parameters include the length of working face, the first weighting interval, and periodic weighting interval. Mechanical parameters of coal and rock mass include elastic modulus, integrity coefficient, and fragmentation coefficient.

The single factor analysis method is used to obtain main influence factors on the breaking position of cantilever beam, as shown in Figure 8 . The distance between the cantilever beam breaking line and coal wall decreases with the increase of coal seam thickness. This is because the greater the coal seam thickness, the larger the rotation space of cantilever beam, and the closer the breaking line is to the coal wall. On the contrary, with the increase of immediate roof thickness, the strata thickness controlled by overburden structure, the length of working face, and the first and periodic weighting interval, the cantilever beam breaking position is gradually transferred to the deep part of coal body.

\section{Numerical Simulation}

4.1. Block Constitutive Model. UDEC is two-dimensional discrete element software for discontinuous medium, which is represented by discrete blocks. Discontinuous surfaces are the contact surfaces between blocks. Blocks can move and rotate along discontinuous surfaces. It is often used to simulate the fracture characteristics and movement laws of overlying strata. In this research, JSET command is used to generate vertical and horizontal joint groups, and CHANGE command is used to change the material properties of blocks and joints [44-47]. Because the tensile strength of rock is significantly lower than the compressive strength, the MohrCoulomb elastoplastic model is chosen as the block constitutive model. The failure envelope of the model conforms to Mohr-Coulomb criterion (shear yield function) with tension cutoff (tension yield function). The failure criterion could be expressed in the plane $\left(\sigma_{1}, \sigma_{3}\right)$, as shown in Figure 9.

The failure envelope is defined from point $A$ to point $B$ by the Mohr-Coulomb yield function [48]:

$$
f^{s}=\sigma_{1}-\sigma_{3} N_{\varphi}+2 c \sqrt{N_{\varphi}}
$$

where $\varphi$ is the friction angle, $c$ is the cohesion, and $N_{\varphi}=$ $1+\sin \varphi / 1-\sin \varphi$ and from $\mathrm{B}$ to $\mathrm{C}$ by tension yield function of the form:

$$
f^{t}=\sigma^{t}-\sigma_{3}
$$

where $\sigma_{t}$ is the tensile strength.

4.2. Contact Constitutive Model. The contact constitutive model is used to simulate the sliding or opening of the contact. It is very proper to show the failure process of overlying strata after excavation of working face $[49,50]$. Figure 10 shows the yielding process of the contact. In the normal direction, the linear relationship between contact stress and displacement is as follows:

$$
\Delta \sigma_{n}=-k_{n} \Delta u_{n}
$$




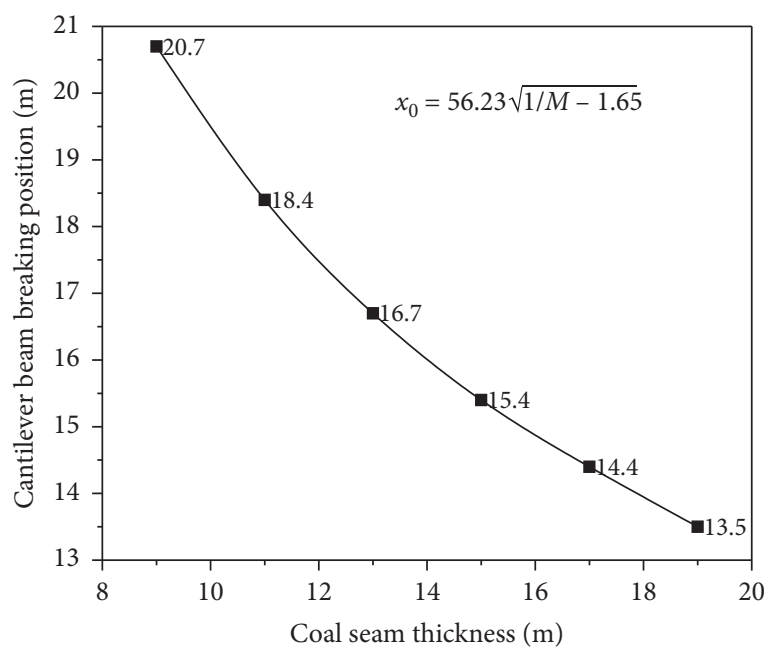

(a)

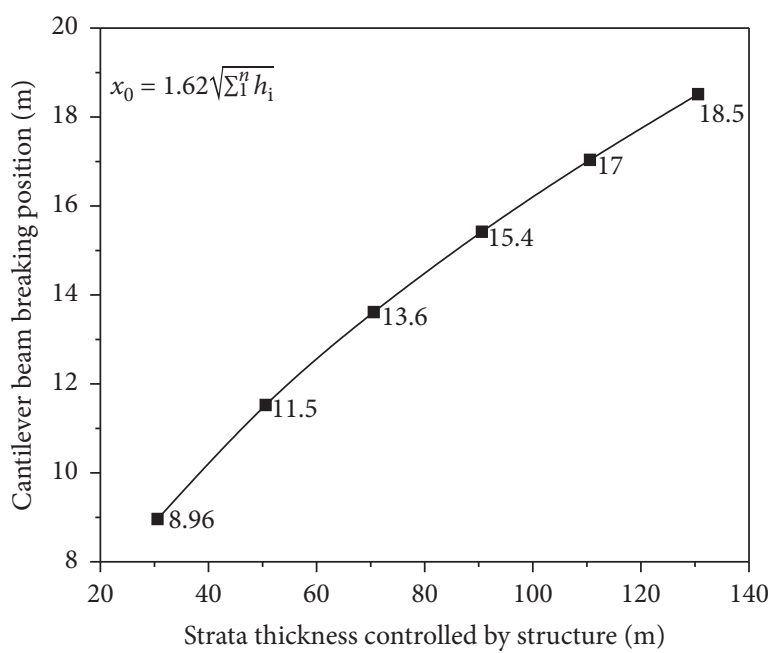

(c)

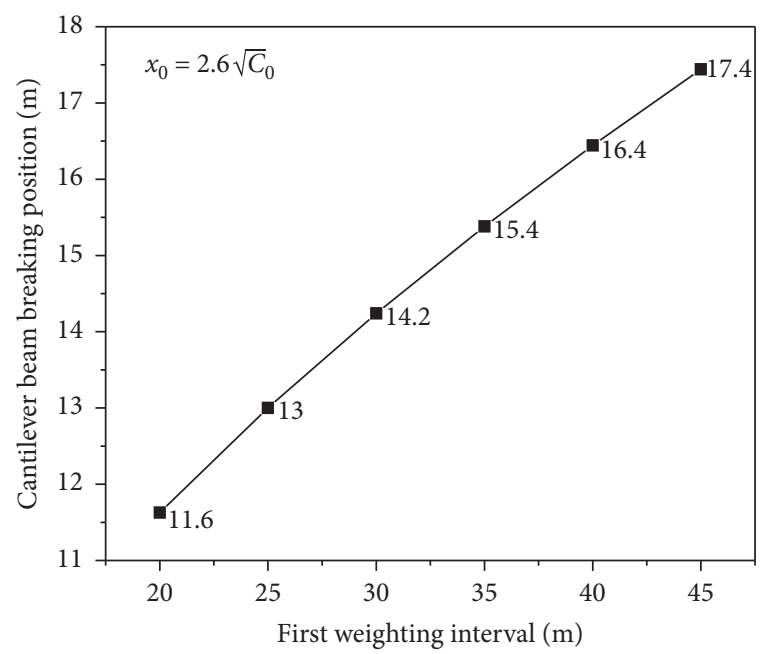

(e)

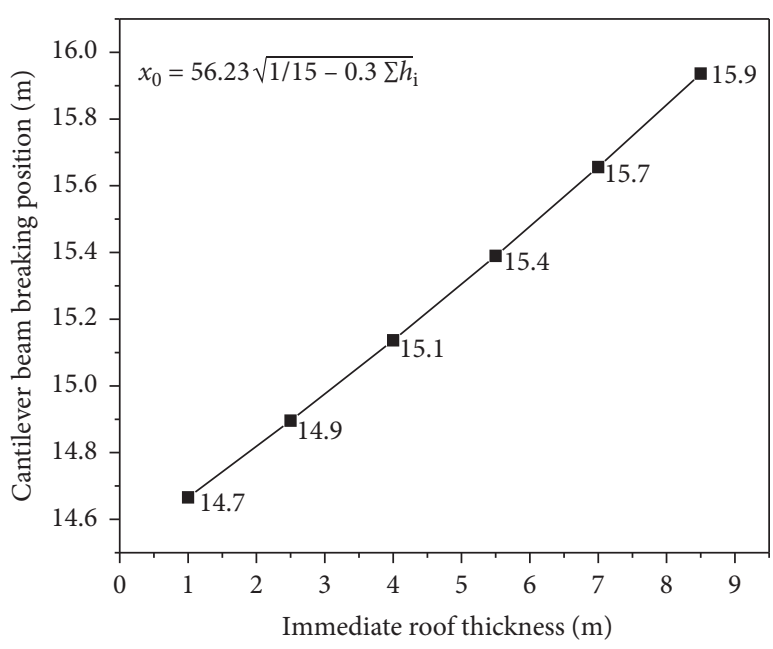

(b)

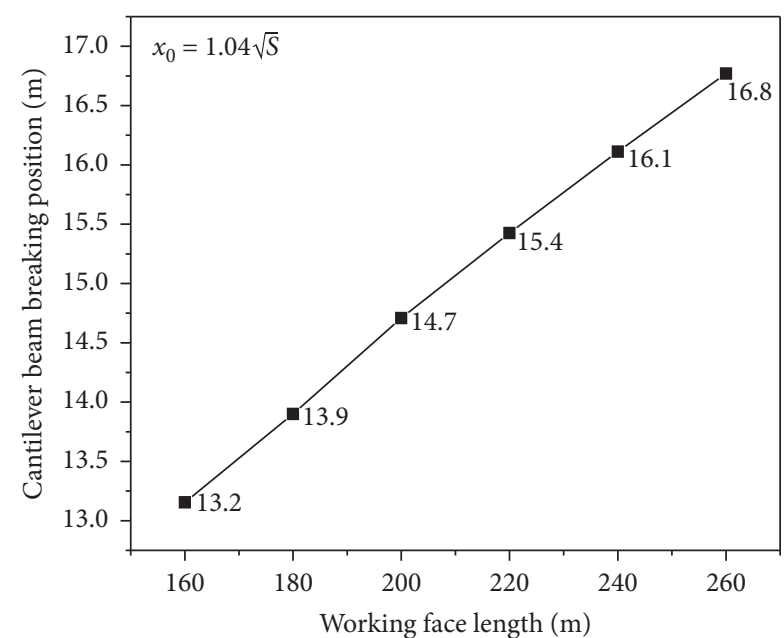

(d)

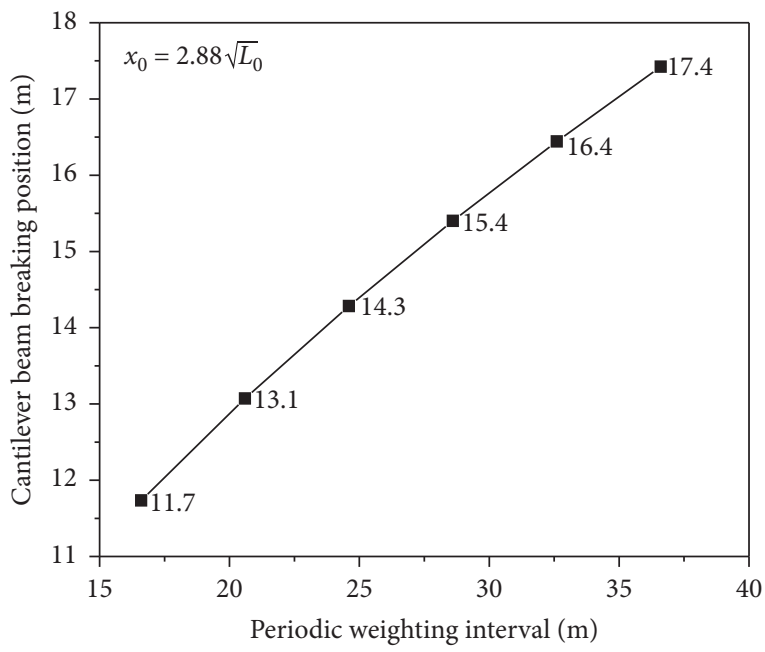

(f)

FIGURE 8: Influence factors of cantilever beam breaking position. (a) Coal seam thickness. (b) Immediate roof thickness. (c) Strata thickness controlled by structure. (d) Working face length. (e) First weighting interval. (f) Periodic weighting interval. 


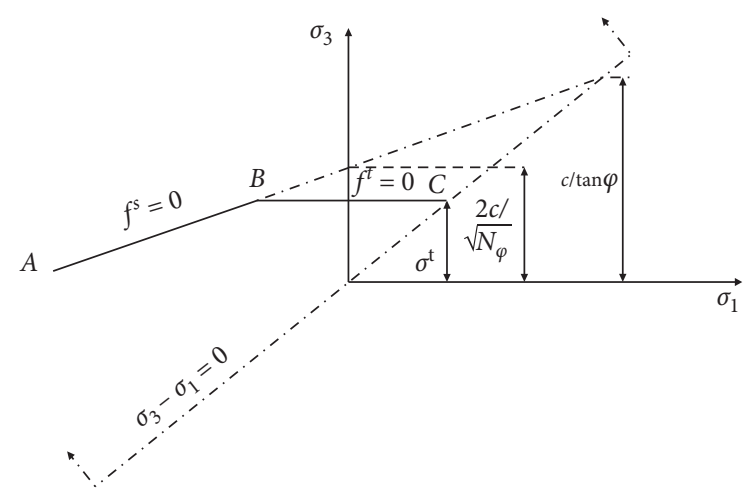

Figure 9: Mohr-Coulomb failure criterion.

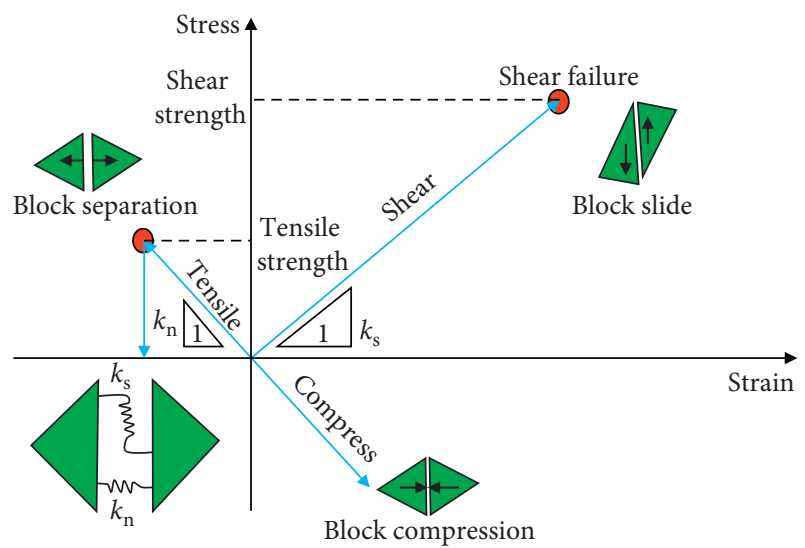

Figure 10: Yielding process of the contact.

where $\Delta \sigma_{n}$ is the normal stress increment; $\Delta u_{n}$ is the normal displacement increment; and $k_{n}$ is the normal stiffness.

If the normal stress is larger than the tensile strength, tensile failure will occur in the contact.

In the shear direction, the response is controlled by the shear stiffness $\left(k_{\mathrm{s}}\right)$ and the shear strength $\left(\tau_{\max }\right)$. The relationship between stress and displacement includes two parts [51].

$$
\text { If } \begin{array}{r}
\left|\tau_{s}\right| \leq c+\sigma_{n} \tan \varphi=\tau_{\max }, \text { then } \\
\tau_{s}=k_{s} \Delta u_{s}^{e},
\end{array}
$$

or else, if $\left|\tau_{s}\right| \geq \tau_{\max }$, then

$$
\Delta \tau_{s}=\operatorname{sign}\left(\Delta u_{s}\right) \tau_{\max },
$$

where $\Delta u_{s}^{e}$ is the elastic shear displacement increment and $\Delta u_{s}$ is the total shear displacement increment.

4.3. Numerical Model Establishment. In order to further judge the key stratum structure morphology of LMTCCM in extra-thick coal seam, the numerical calculation model of UDEC is established, as shown in Figure 11. The width and height of the model are $200 \mathrm{~m}$ and $95 \mathrm{~m}$, respectively. The $X$ axis direction is coal seam inclination, and the $Y$-axis direction is vertical direction. In order to reduce the influence of boundary effect, the excavation length of simulated working face is $100 \mathrm{~m}$. The velocity at the bottom of the model is 0 in the vertical direction. The velocity on both sides of the model is 0 in the horizontal direction. According to the burial depth of working face, vertical stress is applied to the upper boundary to simulate the weight of overburden. The Mohr-Coulomb elastoplastic model is used for blocks, and the Coulomb sliding model is adopted for joints. Based on the previous experiments and X-ray diffraction spectrum of rock samples, the mechanical parameters of blocks and joints are shown in Table 1.

4.4. Structure Failure Characteristics of Key Stratum in Different Cycles. Compared with conventional working face mining, LMTCCM in extra-thick coal seams has its own characteristics. It has large coal seam thickness, mining space, and mining influence, resulting in violent movement of overlying strata and key stratum structure failure. Therefore, in the numerical simulation analysis, the movement characteristics of overlying strata should be reflected as reliably and truthfully as possible, so as to explore the structure characteristics changes of key stratum in different cycles (Figure 12).

When the model cycles 10000, there is no obvious movement of overlying strata and no deformation of coal body. This is because the key strata are not broken and can bear the weight of overlying strata. When the model cycles 50000, the key strata and immediate roof will have a small bending and deformation. Then, the coal body is extruded, resulting in deformation and destruction. When the model cycles 80000 , the immediate roof sinks significantly. The key stratum 1 is broken, and the breakage degree of the key stratum 1 is much greater than that of the key stratum 2 . The key stratum 1 forms stable hinged rock beam structure. When the model cycles 120000, the immediate roof collapses completely. Rotation and subsidence occur in the lower key stratum, which forms cantilever beam structure. The upper key stratum forms hinged structure to support higher strata. The failure of coal body in working face reaches the maximum. Figure 12 shows that, with the increase of cycles, key strata will undergo the evolution law from the generation of longitudinal cracks to the hinged structure and then to the cantilever beam structure. The fracture of the key strata will cause the expansion of longitudinal cracks and the whole synchronous movement of the overlying strata. Under conditions of LMTCCM in extra-thick coal seams, cantilever beam structure is formed in the key stratum 1 and hinged rock beam is formed in the key stratum 2. Numerical simulation results are in agreement with the theoretical calculation.

4.5. Structure Failure Characteristics of Key Stratum in Different Coal Seam Thicknesses. When the coal seam of working face is mined, the movement of overlying strata is gradually stable, and the caving zone, fracture zone, and bending subsidence zone are formed in turn. At this time, the coal body is mainly subjected to static pressure. Coal seam thickness is one of the important factors affecting the breaking state of key stratum. So, UDEC is used to simulate 


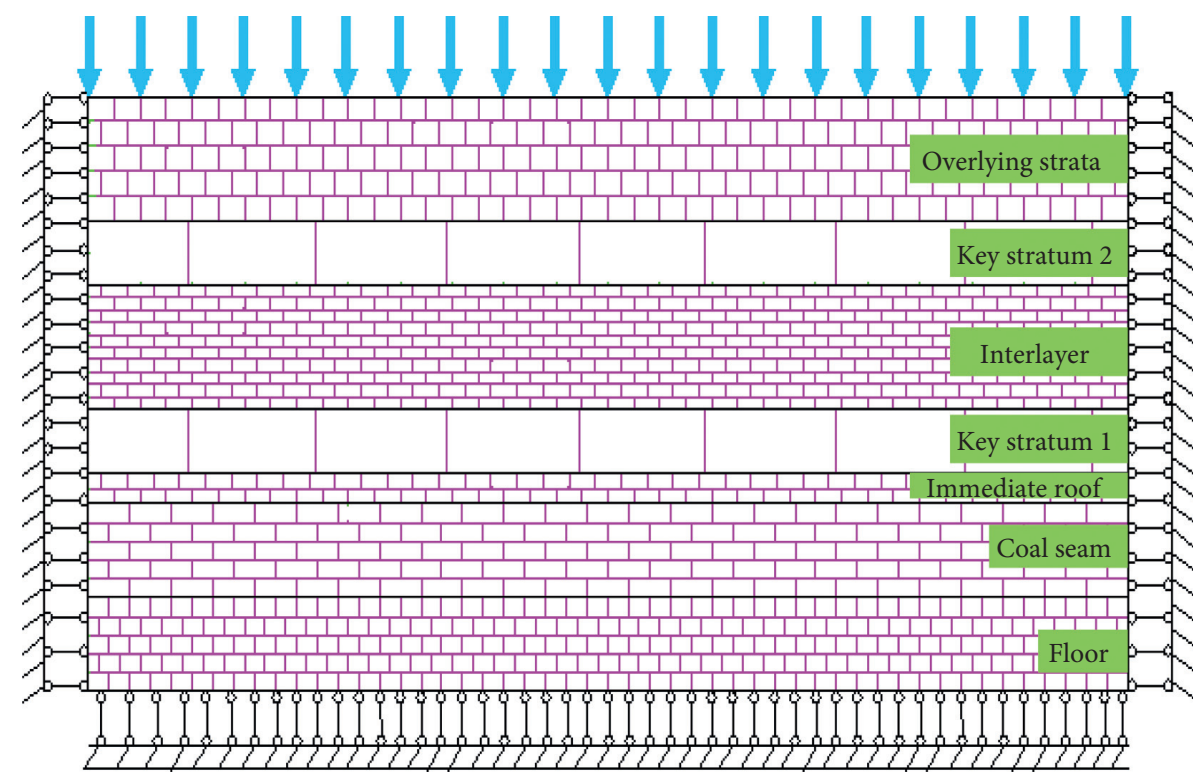

Figure 11: Numerical model.

TABLE 1: The mechanical parameters of blocks and contacts.

\begin{tabular}{lccccccccccc}
\hline \multicolumn{1}{c}{ Lithology } & \multicolumn{4}{c}{ Block properties } & \multicolumn{4}{c}{ Contact properties } \\
& $\begin{array}{l}\text { Density } \\
\left(\mathrm{kg} / \mathrm{m}^{3}\right)\end{array}$ & $K(\mathrm{GPa})$ & $G(\mathrm{GPa})$ & $C^{\mathrm{b}}(\mathrm{MPa})$ & $\varphi^{\mathrm{b}}\left({ }^{\circ}\right)$ & $\sigma_{\mathrm{t}}^{\mathrm{b}}(\mathrm{MPa})$ & $k_{\mathrm{n}}(\mathrm{GPa} / \mathrm{m})$ & $k_{\mathrm{s}}(\mathrm{GPa} / \mathrm{m})$ & $C^{\mathrm{j}}(\mathrm{MPa})$ & $\varphi^{\mathrm{j}}\left({ }^{\circ}\right)$ & $\sigma_{\mathrm{t}}^{\mathrm{j}}(\mathrm{MPa})$ \\
\hline Siltstone & 2538 & 6.36 & 3.28 & 4.0 & 33 & 4.3 & 2640 & 1120 & 0.8 & 11 & 2.1 \\
Sandy mudstone & 2506 & 9.4 & 3.0 & 3.75 & 30 & 3.7 & 2564 & 1049 & 0.75 & 10 & 1.8 \\
Medium sandstone & 2524 & 14.3 & 3.7 & 4.8 & 37 & 4.5 & 2940 & 1520 & 0.96 & 16 & 2.2 \\
Mudstone & 2500 & 2.5 & 1.4 & 3.15 & 26 & 3.1 & 1790 & 1128 & 0.63 & 8 & 1.5 \\
Coal & 1400 & 1.1 & 0.95 & 2.0 & 28 & 2.2 & 1586 & 528 & 0.4 & 9 & 1.1 \\
Fine sandstone & 2550 & 10.6 & 3.5 & 4.5 & 35 & 4.3 & 2740 & 1320 & 0.9 & 13 & 2.05 \\
\hline
\end{tabular}

$K$ is the bulk modulus of blocks; $G$ is the shear modulus of blocks; $C^{\mathrm{i}}$ is the cohesion; $\varphi^{\mathrm{i}}$ is the friction angle; $\sigma_{\mathrm{t}}^{\mathrm{i}}$ is the tensile strength; $k_{\mathrm{n}}$ is the normal stiffness of contacts; $k_{\mathrm{s}}$ is the shear stiffness of contacts.

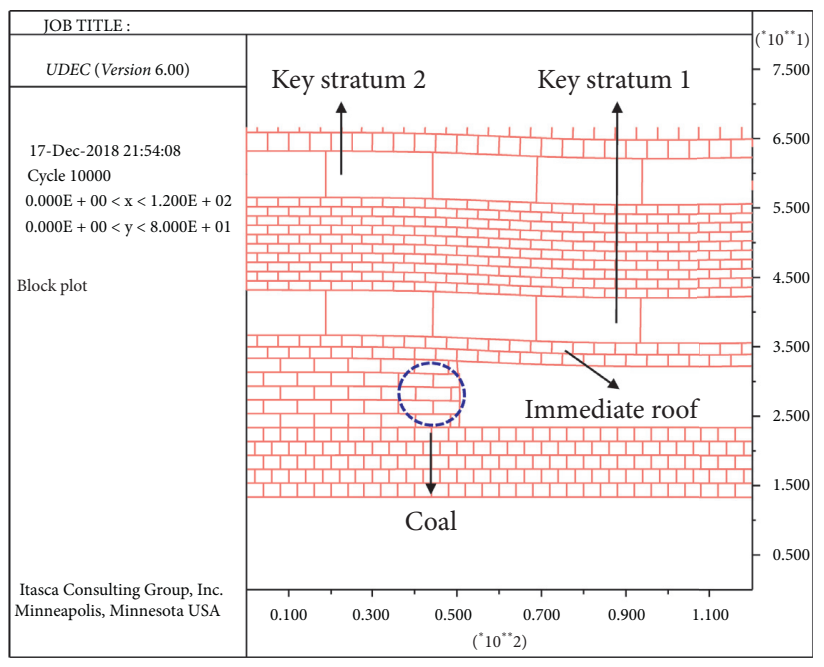

(a)

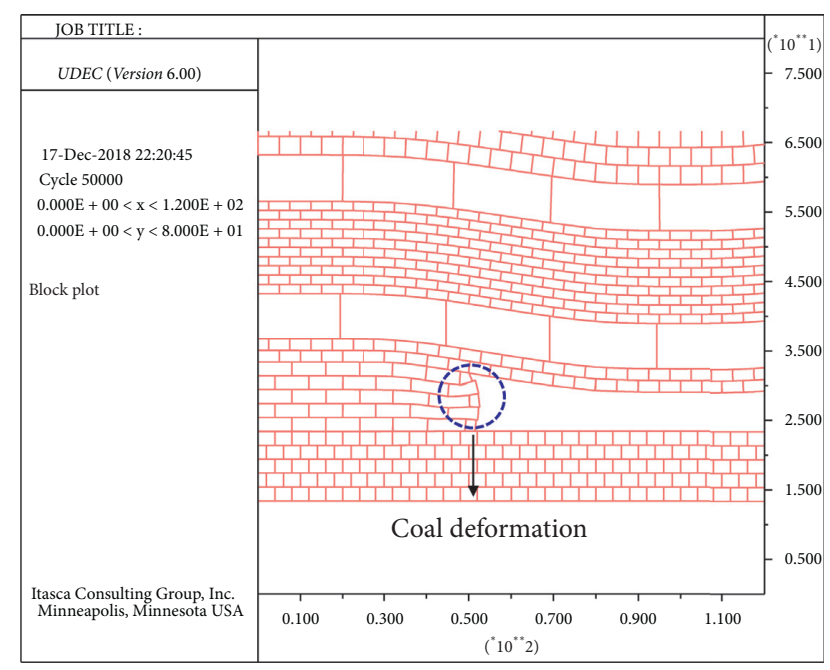

(b)

FIgURE 12: Continued. 


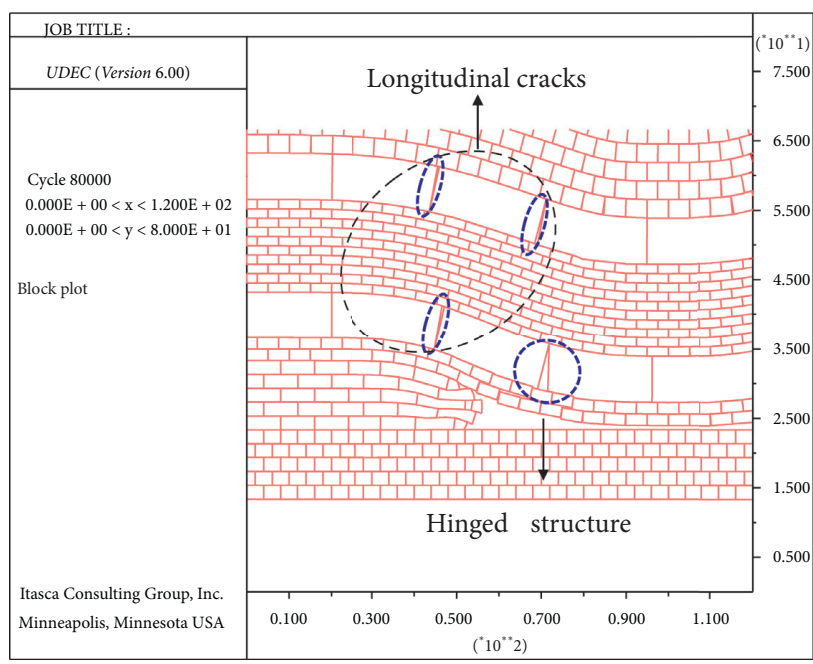

(c)

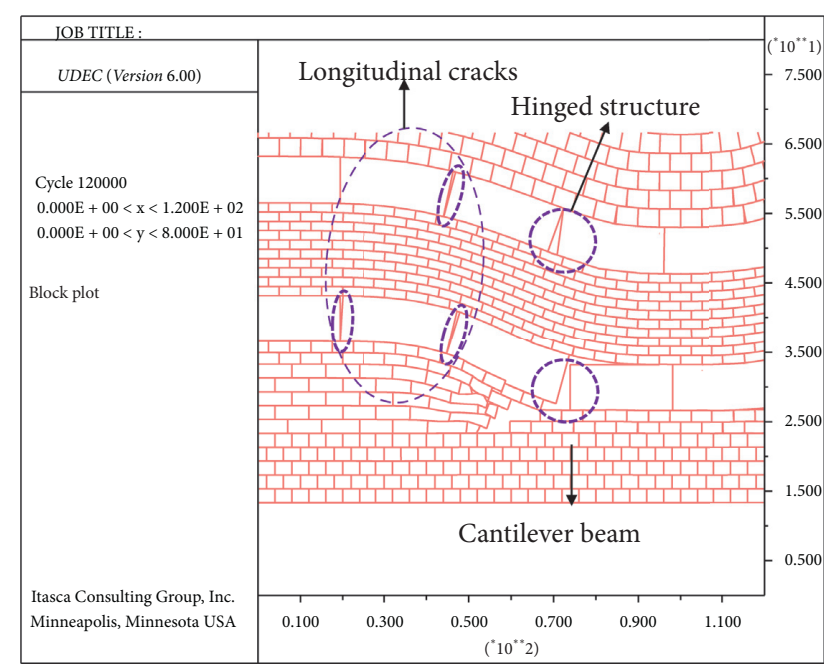

(d)

Figure 12: Structure failure process of key stratum in different cycles. (a) Cycle 10000. (b) Cycle 50000. (c) Cycle 80000. (d) Cycle 120000.

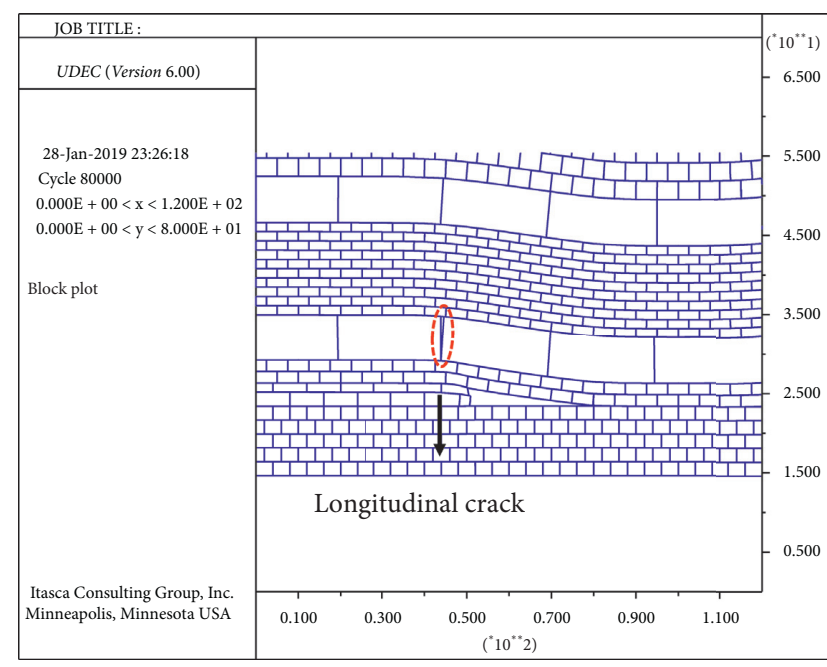

(a)

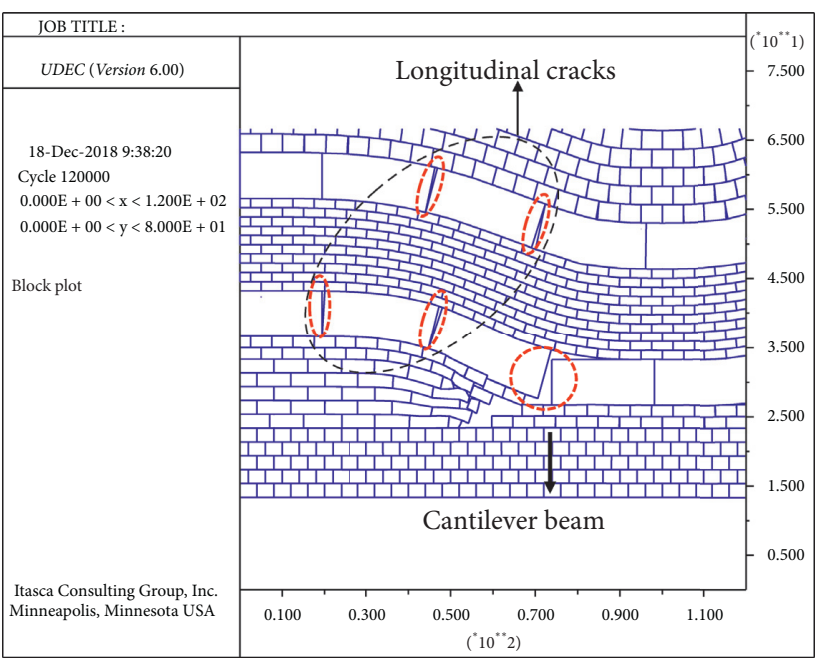

(c)

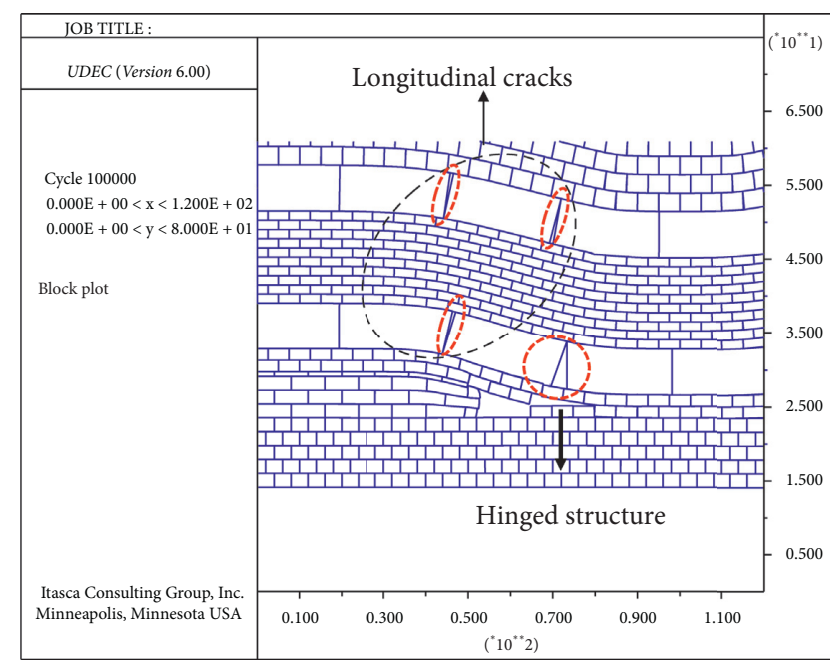

(b)

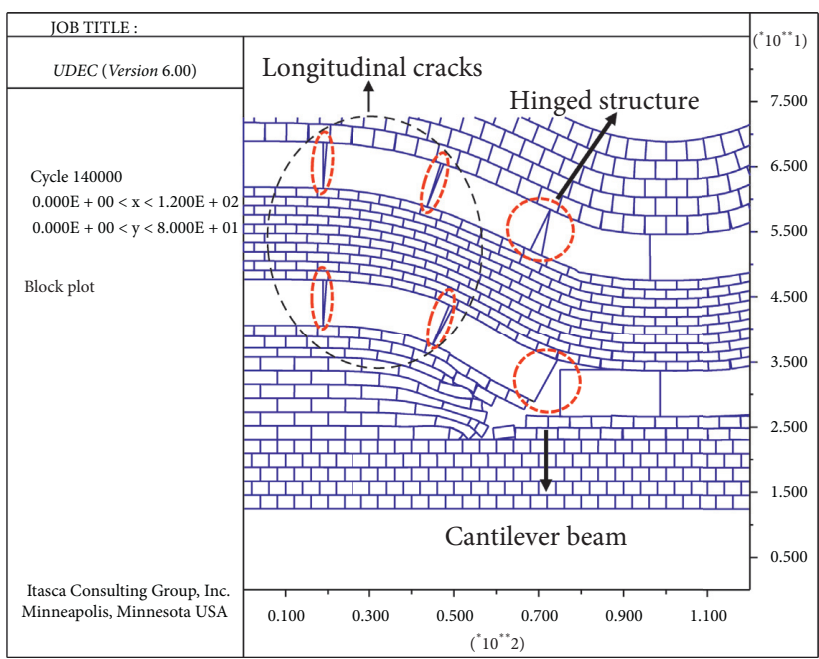

(d)

FIGURE 13: Structure failure characteristics of key stratum in different coal seam thicknesses. (a) $5 \mathrm{~m}$. (b) $10 \mathrm{~m}$. (c) $15 \mathrm{~m}$. (d) $20 \mathrm{~m}$. 
the structure failure characteristics of key stratum in different coal seam thicknesses (Figure 13).

When coal seam thickness is $5 \mathrm{~m}$, overlying strata failure height is relatively small. There is a longitudinal crack in the key stratum 1 . The key stratum 2 and the higher overburden encounter slight synchronous subsidence. When coal seam thickness is $10 \mathrm{~m}$, the key stratum 1 forms stable hinged rock beam structure. There are three longitudinal cracks in the key strata. The rotary force of key strata are transmitted to coal body, which results in large deformation of the coal body. When coal seam thickness is $15 \mathrm{~m}$, the key strata form the low cantilever beam and high hinged rock beam structure. There are three longitudinal cracks in the deep part of coal body. When coal seam thickness is $20 \mathrm{~m}$, the key strata still form the low cantilever beam and high hinged rock beam structure. However, there are four longitudinal cracks in the deep part of coal body. According to the above discussions, it can be seen that, with the increase of coal seam thickness, the distribution of longitudinal cracks will gradually transfer from the upper part of goaf to the deep part of coal body in space and increase in quantity.

\section{Conclusions}

Based on the engineering geological conditions of 8211 working face, theoretical analysis and numerical simulation are used to study the key strata structure morphology of LMTCCM in extra-thick coal seams. The conclusions are as follows:

(1) Under conditions of LMTCCM in extra-thick coal seams, the key strata in the overburden strata form the structure of low cantilever beam and high hinged rock beam. With the increase of coal seam thickness, the breaking position of cantilever beam is closer to the coal wall.

(2) Through theoretical calculation, it is obtained that the breaking length of cantilever beam is $31.5 \mathrm{~m}$ and the breaking position of cantilever beam is $15.4 \mathrm{~m}$ away from coal wall.

(3) The single factor analysis method shows that, with the increase of immediate roof thickness, the strata thickness controlled by overburden structure, the length of working face, and the first and periodic weighting interval, the cantilever beam breaking position is gradually transferred to the deep part of coal body.

(4) With the increase of cycle, key strata will undergo the evolution law from the generation of longitudinal cracks to the hinged structure and then to the cantilever beam structure. The expansion of longitudinal cracks and the whole synchronous movement of overlying strata are beneficial to the prediction of key strata breakage.

\section{Data Availability}

The data used to support the findings of this research are included within the paper.

\section{Conflicts of Interest}

The authors declare that they have no conflicts of interest.

\section{Acknowledgments}

This work was supported by the National Natural Science Foundation of China (No. 51974317), the Yue Qi Distinguished Scholar Project (800015Z1138), China University of Mining and Technology, Beijing, and the Fundamental Research Funds for the Central Universities (800015J6).

\section{References}

[1] M. Chi, D. Zhang, G. Fan, W. Zhang, and H. Liu, "Prediction of top-coal caving and drawing characteristics by the analytic hierarchy process-fuzzy discrimination method in extra-thick coal seams," Journal of Intelligent \& Fuzzy Systems, vol. 33, no. 4, pp. 2533-2545, 2017.

[2] X.-F. Wang, Y. Wang, D.-S. Zhang et al., "Characteristics of strata behavior during thick seam mining by fully-mechanized top coal caving in a loess-covered gullied region," Minerals, vol. 7, no. 4, pp. 63-75, 2017.

[3] S. L. Wu and S. L. Liu, "Study on roof structure model and support-surrounding rock relationship at fully-mechanized coal mining face," Journal of Shandong University of Science and Technology (Natural Science), vol. 35, no. 51, 2016, in Chinese.

[4] J. Zhang, X. Miao, Y. Huang, and M. Li, "Fracture mechanics model of fully mechanized top coal caving of shallow coal seams and its application," International Journal of Mining Science and Technology, vol. 24, no. 3, pp. 349-352, 2014.

[5] B. Yu, J. Zhao, T. Kuang, and X. Meng, "In situ investigations into overburden failures of a super-thick coal seam for longwall top coal caving," International Journal of Rock Mechanics and Mining Sciences, vol. 78, pp. 155-162, 2015.

[6] C. Fan, S. Li, D. Elsworth, J. Han, and Z. Yang, "Experimental investigation on dynamic strength and energy dissipation characteristics of gas outburst-prone coal," Energy Science \& Engineering, vol. 8, no. 4, pp. 1015-1028, 2020.

[7] Z. Q. Song and J. Hao, "An overview of connotation and development of practical ground pressure control theory," Journal of Shandong University of Science and Technology (Natural Science), vol. 38, no. 1, pp. 1-15, 2018, in Chinese.

[8] D. F. Yun, Z. Liu, W. D. Cheng, Z. D. Fan, D. F. Wang, and Y. H. Zhang, "Monitoring strata behavior due to multi-slicing top coal caving longwall mining in steeply dipping extra thick coal seam," International Journal of Mining Science and Technology, vol. 27, no. 1, pp. 179-184, 2016.

[9] Q. Wu, Q. Wu, Y. Xue, P. Kong, and B. Gong, "Analysis of overlying strata movement and disaster-causing effects of coal mining face under the action of hard thick magmatic rock," Processes, vol. 6, no. 9, pp. 150-168, 2018.

[10] X. F. Lv, H. Y. Zhou, Z. W. Wang, and Y. Cai, "Movement and failure law of slope and overlying strata during underground mining," Journal of Geophysics and Engineering, vol. 15, no. 4, pp. 1638-1650, 2018.

[11] C. J. Fan, M. K. Luo, S. Li, H. H. Zhang, Z. H. Yang, and Z. Liu, "A thermo-hydro-mechanical-chemical coupling model and its application in acid fracturing enhanced coalbed methane recovery simulation," Energies, vol. 12, no. 4, pp. 1-20, 2019.

[12] H. Yan, J.-X. Zhang, L.-Y. Li, R.-M. Feng, and T.-T. Li, "Prediction of upper limit position of bedding separation overlying a coal roadway within an extra-thick coal seam," 
Journal of Central South University, vol. 25, no. 2, pp. 448-460, 2018.

[13] L. Fei and Z. Jiang, "Research on deformation mechanism of retracement channel during fully mechanized caving mining in superhigh seam," Advances in Civil Engineering, vol. 2018, Article ID 1368965, 13 pages, 2018.

[14] J. Zhang, "Stability of split-level gob-side entry in ultra-thick coal seams: a case study at Xiegou mine," Energies, vol. 12, no. 4, pp. 628-640, 2019.

[15] S.-C. Wang, L.-M. Dou, Z.-L. Mu, J.-R. Cao, and X.-W. Li, "Study on roof breakage-induced roadway coal burst in an extrathick steeply inclined coal seam," Shock and Vibration, vol. 2019, Article ID 8469019, 14 pages, 2019.

[16] W. Wang, F. Wang, B. Zhao, and G. Li, "Gas distribution law for the fully mechanized top-coal caving face in a gassy extrathick coal seam," Advances in Civil Engineering, vol. 2018, Article ID 3563728, 8 pages, 2018.

[17] J. Wang, B. Yu, H. Kang et al., "Key technologies and equipment for a fully mechanized top-coal caving operation with a large mining height at ultra-thick coal seams," International Journal of Coal Science \& Technology, vol. 2, no. 2, pp. 97-161, 2015.

[18] G. Si, S. Jamnikar, J. Lazar et al., "Monitoring and modelling of gas dynamics in multi-level longwall top coal caving of ultra-thick coal seams, part I: borehole measurements and a conceptual model for gas emission zones," International Journal of Coal Geology, vol. 144-145, pp. 98-110, 2015.

[19] C. Fan, S. Li, M. Luo, L. Zhou, H. Zhang, and Z. Yang, "Effects of $\mathrm{N}$ and $\mathrm{S}$ functionalities on binary gas Co-adsorption on a coal macromolecule," Energy \& Fuels, vol. 33, no. 5, pp. 3934-3946, 2019.

[20] D. W. Zhou, K. Wu, Z. H. Bai et al., "Formation and development mechanism of ground crack caused by coal mining: effects of overlying key strata," Bulletin of Engineering Geology and the Environment, vol. 78, no. 2, pp. 1025-1044, 2017.

[21] W. L. Yao, Z. Yang, and X. Y. Guo, "Fracture development in large-scale overburden strata induced by longwall mining," Energy Sources, Part A: Recovery, Utilization, and Environmental Effects, vol. 41, no. 3, pp. 269-279, 2018.

[22] P. Li, X. Wang, W. Cao, D. Zhang, D. Qin, and H. Wang, "Influence of spatial relationships between key strata on the height of mining-induced fracture zone: a case study of thick coal seam mining," Energies, vol. 11, no. 1, pp. 102-113, 2018.

[23] Y. P. Liang, B. Li, and Q. L. Zou, "Movement type of the first subordinate key stratum and its influence on strata behavior in the fully mechanized face with large mining height," Arabian Journal of Geosciences, vol. 12, no. 2, pp. 31-50, 2019.

[24] L. Jiang, Q. Wu, Q. Wu et al., "Fracture failure analysis of hard and thick key layer and its dynamic response characteristics," Engineering Failure Analysis, vol. 98, pp. 118-130, 2019.

[25] J. Li, Y. Huang, J. Zhang, M. Li, M. Qiao, and F. Wang, "The influences of key strata compound breakage on the overlying strata movement and strata pressure behavior in fully mechanized caving mining of shallow and extremely thick seams: a case study," Advances in Civil Engineering, vol. 2019, Article ID 5929635, 11 pages, 2019.

[26] W. Wang, Y.-P. Cheng, H.-F. Wang et al., "Fracture failure analysis of hard-thick sandstone roof and its controlling effect on gas emission in underground ultra-thick coal extraction," Engineering Failure Analysis, vol. 54, pp. 150-162, 2015.

[27] J. Guo, G. Feng, P. Wang, T. Qi, X. Zhang, and Y. Yan, "Roof strata behavior and support resistance determination for ultra-thick longwall top coal caving panel: a case study of the
Tashan coal mine," Energies, vol. 11, no. 5, pp. 1041-1060, 2018.

[28] Z. Li, J. Xu, J. Ju, W. Zhu, and J. Xu, "The effects of the rotational speed of voussoir beam structures formed by key strata on the ground pressure of stopes," International Journal of Rock Mechanics and Mining Sciences, vol. 108, pp. 67-79, 2018.

[29] J. Sun and X. Miao, "Water-isolating capacity of an inclined coal seam floor based on the theory of water-resistant key strata," Mine Water and the Environment, vol. 36, no. 2, pp. 310-322, 2017.

[30] C. X. Wang, B. T. Shen, J. T. Chen et al., "Compression characteristics of filling gangue and simulation of mining with gangue backfilling: an experimental investigation," Geomechanics and Engineering, vol. 20, no. 6, pp. 485-495, 2020.

[31] N. Jiang, C. Wang, H. Pan, D. Yin, and J. Ma, "Modeling study on the influence of the strip filling mining sequence on mining-induced failure," Energy Science \& Engineering, vol. 8, no. 6, pp. 2239-2255, 2020.

[32] Y. Zhang, S. G. Cao, N. Zhang, and C. Z. Zhao, "The application of short-wall block back fill mining to preserve surface water resources in northwest China," Journal of Cleaner Production, vol. 261, pp. 1-15, 2020.

[33] G. C. Zhang, Z. J. Wen, S. J. Liang et al., "Ground response of a gob-side entry in a longwall panel extracting $17 \mathrm{~m}$-thick coal seam: a case study," Rock Mechanics and Rock Engineering, vol. 53, no. 2, pp. 497-516, 2020.

[34] W. Y. Guo, F. H. Yu, Y. L. Tan, and T. B. Zhao, "Experimental study on the failure mechanism of layer-crack structure," Energy Science \& Engineering, vol. 7, no. 6, pp. 2351-2372, 2019.

[35] G. Zhang, L. Chen, Z. Wen et al., "Squeezing failure behavior of roof-coal masses in a gob-side entry driven under unstable overlying strata," Energy Science \& Engineering, vol. 8, no. 7, pp. 2443-2456, 2020.

[36] Y. C. Xue, W. B. Sun, and Q. S. Wu, "The influence of magmatic rock thickness on fracture and instability law of mining surrounding rock," Geomechanics and Engineering, vol. 20, no. 6, pp. 547-556, 2020.

[37] S. J. Chen, D. W. Yin, N. Jiang, F. Wang, and Z. H. Zhao, "Mechanical properties of oil shale-coal composite samples," International Journal of Rock Mechanics and Mining Sciences, vol. 123, 2019.

[38] G. Feng, Y. Kang, X. Wang, Y. Hu, and X. Li, "Investigation on the failure characteristics and fracture classification of shale under brazilian test conditions," Rock Mechanics and Rock Engineering, vol. 53, no. 7, pp. 3325-3340, 2020.

[39] Q. Yin, G. Ma, H. Jing et al., "Hydraulic properties of 3D rough-walled fractures during shearing: an experimental study," Journal of Hydrology, vol. 555, pp. 169-184, 2017.

[40] M. Li, J.-X. Zhang, Y.-L. Huang, and R. Gao, "Measurement and numerical analysis of influence of key stratum breakage on mine pressure in top-coal caving face with super great mining height," Journal of Central South University, vol. 24, no. 8, pp. 1881-1888, 2017.

[41] J. Ju and J. Xu, "Surface stepped subsidence related to top-coal caving longwall mining of extremely thick coal seam under shallow cover," International Journal of Rock Mechanics and Mining Sciences, vol. 78, pp. 27-35, 2015.

[42] S. Hu, Y. Tan, H. Zhou et al., "Anisotropic modeling of layered rocks incorporating planes of weakness and volumetric stress," Energy Science \& Engineering, vol. 8, no. 3, pp. 789-803, 2020. 
[43] X. Wang, W. Yuan, Y. T. Yan, and X. Zhang, "Scale effect of mechanical properties of jointed rock mass: a numerical study based on particle flow code," Geomechanics and Engineering, vol. 21, no. 3, pp. 259-268, 2020.

[44] S. He, Y. Li, and A. Aydin, "A comparative study of UDEC simulations of an unsupported rock tunnel," Tunnelling and Underground Space Technology, vol. 72, pp. 242-249, 2018.

[45] D. Ren, D. Zhou, D. Liu, F. Dong, S. Ma, and H. Huang, "Formation mechanism of the Upper Triassic Yanchang Formation tight sandstone reservoir in Ordos Basin-Take Chang 6 reservoir in Jiyuan oil field as an examplefield as an example," Journal of Petroleum Science and Engineering, vol. 178, pp. 497-505, 2019.

[46] N. Zhang, W. Liu, Y. Zhang, P. F. Shan, and X. L. Shi, "Microscopic pore structure of surrounding rock for underground strategic petroleum reserve (SPR) caverns in bedded rock salt," Energies, vol. 13, no. 7, pp. 1-22, 2020.

[47] P. Shan and X. Lai, "An associated evaluation methodology of initial stress level of coal-rock masses in steeply inclined coal seams, Urumchi coal field, China," Engineering Computations, vol. 37, no. 6, pp. 2177-2192, 2020.

[48] S. Zhang, D. Zhang, H. Wang, and S. Liang, "Discrete element simulation of the control technology of large section roadway along a fault to drivage under strong mining," Journal of Geophysics and Engineering, vol. 15, no. 6, pp. 2642-2657, 2018.

[49] T. F. Fu, T. Xu, M. J. Heap, P. G. Meredith, and T. M. Mitchell, "Mesoscopic time-dependent behavior of rocks based on three-dimensional discrete element grain-based model," Computers and Geotechnics, vol. 121, 2020.

[50] H. Huang, T. Babadagli, X. Chen, and H. Andy Li, "Performance comparison of novel chemical agents in improving oil recovery from tight sands through spontaneous imbibition," Petroleum Science, vol. 17, no. 2, pp. 409-418, 2020.

[51] C. Zhu, M. C. He, M. Karakus, X. B. Cui, and Z. G. Tao, "Investigating toppling failure mechanism of anti-dip layered slope due to excavation by physical modelling," Rock Mechanics and Rock Engineering, 2020. 